\title{
INTEGRAÇÃOO DAS TECNOLOGIAS DIGITAIS DA INFORMAÇÃO E COMUNICAÇÃO EM CONTEXTOS EDUCACIONAIS: ANÁLISE DE TRÊS MOMENTOS DE UM CURSO OFICIAL DE FORMAÇÃO DE PROFESSORES
}

\section{INTEGRATION OF DIGITAL INFORMATION TECHNOLOGIES AND COMMUNICATION IN LEARNING CONTEXTS: ANALYSIS OF THREE DIFFERENT MOMENTS OF A TEACHER DEVELOPMENT COURSE}

\section{Flávia Danielle Sordi Silva Miranda'}

\section{RESUMO}

Neste artigo, buscamos refletir sobre as relações entre ensino público paulista, tecnologias digitais e letramentos na contemporaneidade por meio da análise de dados coletados em um estudo de caso composto por três momentos de uma formação continuada do Programa Nacional de Formação Continuada em Tecnologia Educacional (Prolnfo Integrado), a saber, (i) material de um dos cursos do programa, o "Tecnologias na Educação: ensinando e aprendendo com as TICs", (ii) aplicação desse curso por uma tutora a professores da rede do interior de São Paulo e (iii) prática de sala de aula de uma professora cursista. O objetivo específico foi identificar quais dos discursos mais comuns envolvendo letramentos e tecnologias eram percebidos em cada momento da formação, a partir da distinção de Warschauer e Ware (2008) em "enquadre da aprendizagem", "enquadre da mudança" e "enquadre do empoderamento" e apontar para as articulações existentes entre eles. Trata-se de pesquisa qualitativa, de cunho etnográfico, em que os dados foram gerados ao seguirmos e gravarmos as diversas fases dos encontros presenciais, observarmos as interações e atividades dos cursistas na plataforma on-line, de entrevistas com a tutora e com os cursistas, além da análise de documentos e dos materiais referentes ao curso e do acompanhamento e registro de aulas de uma professora cursista na escola de Educação Básica em que leciona. Os pressupostos teóricos foram baseados na concepção enunciativa sóciohistórica sobre língua e na concepção de gêneros discursivos de Bakhtin. Os resultados obtidos apontaram para diversas articulações entre ensino e tecnologias que permearam os contextos estudados e para a dificuldade de distinção entre os discursos, posto que não há separações demarcadas entre eles. Palavras-chave: ensino público paulista; tecnologias; letramentos.

\footnotetext{
*UNICAMP, Campinas (SP), Brasil. flaviasordi@gmail.com
} 


\section{ABSTRACT}

The aim of this article is to analyze the correlations between São Paulo's public state schools, digital technologies and literacies in the contemporaneity using the analysis of data from a case study composed of three moments of the National Program for Continuing Education in Educational Technology (Integrated ProInfo), namely, (i) the material used in 'Technologies in Education: teaching and learning with ICT', a course in the program, (ii) the application of this course by a teacher tutor for public schools teachers of São Paulo's countryside and (iii) the classroom practice of a teacher. The specific objective was to identify which of the most frequent discourses involving literacy and technologies were noticed in each specific moment of the education, from Warschauer and Ware (2008) distinction in "learning framework", "change framework" and "power framework" and point to the articulations which exist among them. It is a qualitative research, of an ethnographic nature, in which the data were generated as the various stages of the lessons were observed and recorded, as well as the observation of the interactions and activities of the course participants in the online platform; interviews with the tutor and course participants were conducted; besides the analysis of documents and materials related to that course and the monitoring and recording of the lessons of one of the teachers in charge at the school where she teaches. The theoretical assumptions are based on the socio-historical enunciative conception of language and Bakhtin's conception of speech genres. The results pointed to several articulations between teaching and technologies that permeated the contexts studied and the difficulty of distinguishing between discourses, since there is no marked separation between them.

Keywords: São Paulo’s public education; technologies; literacies.

\section{INTRODUÇÃO}

Em suma, um dos principais problemas do debate sobre tecnologia e educação - e um dos sintomas de sua imaturidade - é que está demais polarizado como debate entre os entusiastas e seus oponentes. Aqueles que questionam ou contestam os usos das ICTs na educação são muito rapidamente taxados de tecnofóbicos, pré-bistóricos ou ludistas, que se opõem sem razão ao progresso; ao passo que os que professam os benefícios da tecnologia são, talvez, facilmente estereotipados como ingênuos e irrealistas em suas aspirações. Enquanto isso, tem-se marginalizado questões fundamentais sobre como professores e alunos poderiam querer usar a tecnologia e sobre o que precisamos saber acerca dela (BUCKINGHAM, 2010, p. 42).

No contexto mundial, a difusão acentuada das Tecnologias Digitais de Informação e Comunicação - TDIC - e, principalmente, da Internet, data do final do século XX e, com ela, o debate sobre tecnologias/educação e tecnologias/letramentos ganhou tônica no cenário de discussão, à medida que se viu, algumas vezes, muito rápido e claramente, transformações nos modos e suportes materiais pelos quais se transmitiam e construíam conhecimentos. Com isso, parece ter se formado uma 
polarização entre aficionados em relação à incorporação das tecnologias ${ }^{1}$ digitais no ensino e os contrários a essa integração.

Já, nesses primeiros anos do século XXI, vivenciamos uma história que ainda está sendo escrita e que traz novos elementos para serem pensados em relação ao ensino e à linguagem: globalização, conectividade, uso social de tecnologias digitais (fora da escola), práticas digitais realizadas por estudantes diariamente, subsídios de secretarias estaduais de educação para que os professores adquiram computadores, surgimento de novas práticas letradas.

Diante disso, neste artigo, trataremos do debate sobre tecnologias e educação no que tange à questão dos letramentos. Para tanto, a investigação perpassou três momentos de uma formação continuada do Programa Nacional de Formação Continuada em Tecnologia Educacional (ProInfo Integrado): (i) material digital e impresso do curso, (ii) a aplicação do módulo "Tecnologias na Educação: ensinando e aprendendo com as TIC" por uma tutora em uma diretoria do interior de São Paulo a professores da rede e (iii) a prática de uma docente que frequentara o curso, envolvendo seus alunos da Educação Básica.

Com efeito, sabe-se que há diversos enquadres no que tange à relação entre os termos "tecnologias" e "letramentos" que poderiam ser utilizados como ancoragem para discutir sobre o que isso significa para o ensino-aprendizagem em relação aos contextos abordados. Neste trabalho, optamos por tomar como base os três discursos mais comuns, distinguidos por Waschauer e Ware, no texto "Learning, change, and power: competing discourses of technology and literacy" ("Aprendizagem, Mudança e poder: contrapondo discursos de tecnologia e letramento"), publicado em 2008, embora se tenha consciência de que outros existam e em outras situações poderiam ser, inclusive, mais pertinentes.

Finalmente, tencionamos observar se, de fato, esses três enquadres aparecem entre as posições que subjazem as representações de nosso contexto de estudo e, quando identificados, verificar quais deles são os mais frequentes e como estão articulados às ações que se dão nos três momentos do curso de formação enfocado, ressalvando que, na prática, esses enquadres se dão concomitantemente uns aos outros e não são os únicos existentes, tampouco possíveis.

\footnotetext{
1 É importante destacar que a palavra "tecnologias" pode ser tomada a partir de diferentes perspectivas para se referir às técnicas aplicadas nas práticas sociais. Nesse sentido, elementos anteriores ao digital, como lousa, caderno, giz etc ou mesmo luz elétrica, elevador, eletrodomésticos também são tecnologias. Por isso, ressaltamos que, neste trabalho, quando usado o termo, estaremos nos referindo às tecnologias digitais de comunicação e informação (TDIC).
} 


\section{ALGUMAS POSSÍVEIS RELAÇÕES ENTRE LETRAMENTOS E TECNOLOGIAS: CONHECENDO ENQUADRES}

O primeiro enquadre definido por Warschauer e Ware (2008, p. 216-220), "enquadre de aprendizagem" (Learning framework), centra-se nos modos como os estudantes que usam as tecnologias poderiam aumentar seu aprendizado e, focaliza, por isso, elevação nas pontuações (scores) sobre leitura e escrita em testes padrões, priorizando estudos quantitativos. Nessa perspectiva, computadores e Internet seriam novas formas de mídia educacional, assim como o rádio e a televisão já o são.

Pesquisas dentro desse ponto de vista limitam-se à aplicação de experimentos ou análises correlacionadas. A crítica a tal discurso, segundo os autores, reside no fato de que se busca, com base nessa postura, implantar tecnologias nas escolas por meio da introdução de computadores, por exemplo, para elevar o desempenho dos alunos em testes que são, contraditoriamente, baseados em práticas tradicionais de letramento ainda fundamentadas no impresso.

Em um aspecto, pelo menos, esse enquadre proposto pelos autores é problemático: os autores consideram que seria possível aprender (learning) separadamente à ação de transformar (change) e do empoderamento (power) dos sujeitos envolvidos na aprendizagem, como voltaremos a falar mais adiante.

No entanto, o segundo enquadre, que seria mais frequente para os autores, não exclui e tampouco se opõe ao primeiro: seria o "enquadre da mudança" (change framework), isto é, discurso baseado no entendimento das tecnologias como portadoras de transformações revolucionárias para práticas de leitura, escrita, comunicação e, por conseguinte, produção de conhecimento, à medida que não se restringe à funcionalidade da aprendizagem, mas transcende-a e pensa na tecnologia digital como elemento para se efetivar uma reforma educacional mais ampla.

Ainda para os autores (p. 220), pode-se comparar essa perspectiva às intensas mutações sofridas, por exemplo, com o desenvolvimento da linguagem, da escrita e do impresso, sendo, assim, uma espécie de " 4 a revolução" no que tange à produção de conhecimento.

Ainda nesse eixo da mudança, a escola seria colocada em cheque, acusada de instituição conservadora e, assim, é proposta uma mutação radical na educação, substituindo modos tradicionais de ensino. Nesse sentido, três áreas bastante investigadas são a multimídia, a comunicação digital e os letramentos associados com jogos de vídeo-game (p. 223). Geralmente, suas pesquisas focam práticas extraescolares e estabelecem metodologia etnográfica em que estudiosos exploram o meio social e cultural em que aquelas práticas são desenvolvidas. 
A crítica para essa perspectiva consiste no fato de que não seria óbvio crer que somente porque os letramentos são novos, haveria benefícios para aqueles expostos a eles (p. 227).

Por fim, para os autores (p. 227), "enquadre do empoderamento" (power framework) seria o discurso mais complexo dos três. Essa perspectiva compartilharia com a primeira já apresentada, a noção de que a ação educacional na escola é muito importante e reconhece o valor dos testes padronizados, porém, focaliza não somente os índices, mas como contextos sociais, econômicos, culturais e linguísticos podem dar acesso aos estudantes à educação, letramentos, empreendimento acadêmico e levá-los a apropriarem-se dos usos da tecnologia para fins desejados.

Com a segunda perspectiva, teria em comum a visão de que os letramentos estão em estado de fluxo rápido de mudanças e, portanto, novas habilidades digitais e domínio de determinados gêneros são exigidos aos estudantes que, ao conseguirem dominá-los, estariam recebendo poder ${ }^{2}$. Em contrapartida, prioriza relações formadas por tecnologias e práticas letradas que parecem ser mais intimamente ligadas ao social, econômico, cultural, especialmente, aquelas marginalizadas.

Desse modo, nesse enquadre, requer-se equilíbrio entre o determinismo das TDIC e o protagonismo dos sujeitos sobre a tecnologia, a fim de "empoderar" jovens através do conhecimento, acesso e competências com ferramentas socialmente relevantes (p. 227-223).

Para esclarecer as diferenças mais significativas entre os enquadres delineados pelos autores e visando às análises que seguem, elaboramos o Quadro 1, sintetizando os aspectos mais representativos de cada um deles e também com base em Warschauer e Ware (2008) o que consideramos como os aspectos frágeis de cada postura:

2 O termo power utilizado por Warschauer e Ware (2008) pode levar, em contexto brasileiro, à equivocada interpretação de ser compatível com as ideias de Paulo Freire (1970) e da educação como meio de "dar" poder aos sujeitos envolvidos, posição essa com a qual comungamos. Todavia, essa conotação se aproxima mais daquilo que os autores chamam de "enquadre da mudança" do que do "enquadre do empoderamento". 
Quadro 1. Diferenças entre os principais discursos envolvendo tecnologias e letramentos distinguidos por Warschauer e Ware (2008)

\begin{tabular}{|l|l|l|l|}
\hline $\begin{array}{c}\text { Diferencia- } \\
\text { ções quanto à }\end{array}$ & \multicolumn{1}{|c|}{$\begin{array}{c}\text { Learning Fra- } \\
\text { mework }\end{array}$} & \multicolumn{1}{|c|}{ Change Framework } & \multicolumn{1}{|c|}{ Power Framework } \\
\hline Ênfase & $\begin{array}{l}\text { Avaliar impactos } \\
\text { dos usos da tec- } \\
\text { nologia no ensino }\end{array}$ & $\begin{array}{l}\text { Reconhecer as transfor- } \\
\text { mações revolucionárias } \\
\text { trazidas pelas tecnologias } \\
\text { e tornar a escolarização } \\
\text { relevante por considerar os } \\
\text { novos letramentos }\end{array}$ & $\begin{array}{l}\text { Considerar que práticas le- } \\
\text { tradas são sociais e apresen- } \\
\text { tam estruturas desiguais de } \\
\text { poder/ Possibilidade dos usos } \\
\text { da tecnologia como formas } \\
\text { de empoderamento }\end{array}$ \\
\hline $\begin{array}{l}\text { Pontos Posi- } \\
\text { tivos }\end{array}$ & $\begin{array}{l}\text { Busca pelo au- } \\
\text { mento de habili- } \\
\text { dades de leitura e } \\
\text { escrita dos estu- } \\
\text { dantes }\end{array}$ & $\begin{array}{l}\text { Compreender como os le- } \\
\text { tramentos têm sido trans- } \\
\text { formados }\end{array}$ & $\begin{array}{l}\text { Ponderar como os le- } \\
\text { tramentos estão imbri- } \\
\text { cados a relações de po- } \\
\text { der que são desiguais/ }\end{array}$ \\
\hline $\begin{array}{l}\text { Pontos Críti- } \\
\text { cos }\end{array}$ & $\begin{array}{l}\text { Reduzir o ensino } \\
\text { a performances } \\
\text { para testes e fo- } \\
\text { car nos impactos } \\
\text { dos usos da tec- } \\
\text { nologia }\end{array}$ & $\begin{array}{l}\text { Não buscar compreender } \\
\text { e/ou explicar consistente- } \\
\text { mente o que as transforma- } \\
\text { ções significam }\end{array}$ & $\begin{array}{l}\text { Dificuldade de se encontrar } \\
\text { uma medida entre o deter- } \\
\text { minismo e a agentividade no } \\
\text { uso das tecnologias }\end{array}$ \\
\hline
\end{tabular}

Esclarecidas as distinções entre os enquadres, buscaremos, na análise, identificar, ancorados nas distinções dos autores, os discursos que subjazem às posições veiculadas nos três momentos da formação quanto a tecnologias e letramentos, bem como à frequência com que aparecem.

\section{TECNOLOGIAS DIGITAIS E LETRAMENTOS: COMO FICA A QUESTÃO DO EN- SINO?}

Sabe-se que muitos dos alunos, inclusive os da rede pública de ensino, independentemente do grupo socioeconômico ao qual pertencem, participam de práticas letradas que envolvem as tecnologias digitais, como o uso de aparelhos celulares e da própria Internet, ainda que não possuam computa- 
dores próprios, acessando-os em outros locais como instituições de ensino, casa de amigos ou familiares e locais públicos de acesso gratuito. ${ }^{3}$

Por outro lado, a despeito desse intenso uso da Internet e de práticas letradas mediadas por computadores, vê-se que são poucas as práticas em contexto escolar que se valem, efetivamente, daquilo que já é praticado pelos alunos fora das salas de aula por uma série de fatores, como falta de recursos materiais e financeiros, ausência de estruturas físicas e, até mesmo, receio de docentes diante das novas possibilidades imprevistas que são postas em uso quando se permite a utilização das tecnologias digitais (VALENTE, 1993).

Em meio a esse cenário, nos últimos anos, percebe-se "tendência a uma convocação de professores pelo Estado para que retornem à sala de aula para remediar uma formação quase sempre avaliada como insuficiente" (DE GRANDE, 2011, p. 145), por meio de capacitações e formações continuadas ${ }^{4}$ o que inclui cursos voltados para a consciência tecnológica do professor visando a auxiliá-lo no uso das TDIC em sua prática docente, ${ }^{5}$ como espécie de resposta governamental para uma demanda da sociedade (reivindicada pela mídia, pela família, pelo mercado, pelas relações internacionais etc). Essas políticas públicas são, também, oriundas do cenário político (neoliberal):

Dentro desse contexto de regulação neoliberal, a educação ganha centralidade devido ao fato de representar a base para o desenvolvimento científico e tecnológico, num espaço em que a ciência e a tecnologia vêm se transformar paulatinamente em forças produtivas (BRESSANI, 2012, p. 46-47).

3 Como mostraram os dados divulgados pela pesquisa do Centro de Estudos sobre as Tecnologias da Informação e da Comunicação (CETIC) acerca da frequência do acesso do aluno à internet, $70 \%$ dos alunos de $8^{\mathrm{a}}$ série $/ 9^{\circ}$ ano e $73 \%$ dos alunos do $2^{\circ}$ ano do Ensino Médio utilizam a internet todos os dias ou quase. Isto se aplica, principalmente, à chamada "geração adolescente". Dados retirados de B9b "Frequência do acesso do aluno à internet". Fonte: http://www.cetic.br/educacao/2011/a-perf-usuar09b.htm. Consultado em 22 Abr. 2013.

Além disso, de acordo com números levantados em "Gerações Interativas Brasil - Crianças e Jovens diante das Telas" pelo Fórum Gerações Interativas, Ibope, Escola do Futuro da USP e Fundação Telefônica divulgada em setembro de 2012, 75\% dos adolescentes entre 10 e 18 anos acessam constantemente a internet. Fonte: http://grupodeestudoscomunica.blogspot.com.br/2012/09/as-geracoes-interativas.html. Consultado em 23 nov. 2012.

4 Foi por meio da LDB Lei n ${ }^{\circ} .9 .394$ de 1996 que se oficializou a formação continuada de professores, a qual recebeu acréscimos treze anos mais tarde em que se reconheceu o ensino à distância como válido também nessa formação com a Lei nº 12.056 de 2007.

5 Alguns exemplos que poderiam ser citados são "Introdução à Educação Digital", "Elaboração de projetos", "Curso especializado de Tecnologias em Educação" e "Tecnologias na educação". Ver http://portal.mec.gov.br/index.php?option $=$ com_content\&view $=$ article\&id $=13156$. Consultado em 13 Ago. 2012. 
Dada essa íntima relação entre educação e forças político-sociais, assiste-se à proliferação de ações e programas educacionais, traduzidos, muitas vezes, em cursos $^{6}$ de formação continuada (ligados ou não ao digital) para professores de Educação Básica, da rede pública de ensino brasileira, os quais, não raras vezes, recebem auxílio de instituições particulares nacionais e estrangeiras.

A criação desses programas, no contexto brasileiro, é, geralmente, justificada por certa demanda social advinda de tendências exigidas pelo mundo globalizado, como o uso cotidiano das tecnologias digitais. No caso do Proinfo, uma de suas metas é promover a capacitação de professores com o objetivo de fomentar mudanças educacionais no que toca à presença das $\mathrm{TDIC}$, ou seja, trata-se de réplica ao que o Estado supõe como seu outro: a globalização. Segundo Straub (2012, p. 158) "No discurso governamental, para que a educação tenha melhoria, é necessário que o sujeito esteja conectado com o mundo, e é para isso que o governo lança os programas ProInfo" 7 .

De acordo com o "Guia do cursista" encontrado no material do curso, (BRASIL, 2007, apud ALMEIDA; PRADO; TORGAGHI, 2010, p. 7), depois da reforma, foram imputados ao programa três elementos:

- a instalação de ambientes tecnológicos nas escolas: laboratórios de informática com computadores, impressoras e outros equipamentos, e acesso à internet - banda larga;

- a organização de conteúdos e recursos educacionais multimídia e digitais, soluções e sistemas de informação disponibilizados pela SEED/MEC nos próprios computadores, por meio do Portal do Professor, da TV Escola etc;

- a formação continuada dos professores e outros agentes educacionais para o uso pedagógico das Tecnologias de Informação e Comunicação (TICs).

\footnotetext{
6 Alguns exemplos nesse sentido, na Educação Básica, são o "Programa Gestão da Aprendizagem escolar (GESTAR)" que oferece formação continuada para professores de Português e Matemática do Ensino Fundamental II ou o "Pró-Letramento - Mobilização pela qualidade da educação", o qual visa melhoras na qualidade de leitura/escrita e matemática de professores das séries iniciais. Todos eles com o intuito de chamar o professor novamente às salas de aula para preencherem eventuais lacunas em suas formações iniciais.

7 Estabelecido ainda no século XX - Portaria n 522 de 9 de abril de 1997 - o programa chamava-se, inicialmente, Programa Nacional de Informática na Educação. Logo em sua criação, em 1997, o objetivo geral era o de "disseminar o uso pedagógico das tecnologias de informática e telecomunicações nas escolas públicas de ensino fundamental e médio pertencentes às redes estadual e municipal" (BRASIL, 1997, Art. $1^{\circ}$ ). No governo posterior, o programa foi apurado com o Decreto Presidencial $n^{\circ} 6300$ de 12 de dezembro de 2007 e recebeu nova (e até então atual) designação.
} 
O enfoque deste trabalho está no terceiro elemento, ou seja, na formação continuada de professores e o recorte se dará na aplicação do ProInfo Integrado no estado de São Paulo e, especificamente, em uma cidade de seu interior (Ribeirão Preto), com o curso "Tecnologias na Educação: ensinando e aprendendo com as TICs" ${ }^{\prime \prime}$

\section{METODOLOGIA}

As aulas presenciais do curso do ProInfo aconteceram na própria DE-RP, entre junho e outubro de 2012 e foram acompanhadas ${ }^{9}$ pela pesquisadora que recebeu autorização para a observação e também foi matriculada como cursista, embora não fosse professora da rede pública do Estado.

No que tange à esfera do curso "Tecnologias na Educação: ensinando e aprendendo com as TICs" do ProInfo, os dados referem-se a:

a. Plataforma colaborativa on-line disponível em http://eproinfo.mec.gov.br/i

b. CD-Room com o conteúdo completo do curso (textos + atividades);

c. Quatro apostilas impressas: Unidade 1 "Tecnologias de informação e Comunicação", Unidade 2 "Internet, Hipertexto e Hipermídia", Unidade 3 "Currículo, projetos e tecnologias" e Unidade 4 "Prática pedagógica e mídias digitais".

Em relação à aplicação do curso pela tutora $A$, os dados referem-se a:

a. Gravações em áudio dos oito encontros presenciais ministrados pela tutora na DE-RP, num total de 11 horas e 25 minutos de gravação;

8 O ProInfo também oferece os cursos "Introdução à Educação Digital" e "Elaboração de Projetos".

9 "Tecnologias na Educação: ensinando e aprendendo com as TICs" contou com 100 horas dividias entre encontros presenciais (36 horas) coordenados pela tutora $A$ e o restante do trabalho à distância em uma plataforma colaborativa, chamada de e-Prolnfo e disponível em http://eproinfo.mec.gov. $\mathrm{br} /$. Os encontros não foram contínuos, mas marcados com intervalos para que os alunos pudessem fazer as atividades em casa. Recomenda-se, pelos organizadores, que sejam nove encontros Além disso, como a tutora do curso em questão também é funcionaria da DE-RP e desempenhava, portanto, outras funções para as quais tinha de se ausentar da cidade, algumas aulas presenciais foram remanejadas para outros dias do mês e mesmo da semana. Assim, sendo, os encontros do curso ocorreram em: 27/06, 20/07, 25/07, 01/08, 08/08, 15/08, 05/09, 12/09, 19/09 e 03/10. Além disso, é preciso ressaltar que, caso o cursista não pudesse comparecer ao presencial, havia a possibilidade de agendar um horário de reposição com a tutora, visto que para receber o certificado era preciso frequência de $80 \%$, além de uma nota média acima de sete na somatória das atividades. 
b. Diários de campo dos encontros presenciais (oito diários de campo);

c. Arquivos dos 15 power points preparados pela tutora para os encontros presenciais;

d. Anotações sobre as quatro entrevistas semi estruturadas realizadas com a tutora em horários distintos dos encontros presenciais, também na DE-RP, em 25-05-2012, 01-06-2012, 05-06-2012 e 05-10-2012, respectivamente;

Enfim, acerca do desenvolvimento dos professores cursistas no curso em questão e em suas práticas docentes, os dados referem-se a:

a. Questionário aplicado aos cursistas em 19-09-2012 no penúltimo encontro presencial ocorrido na DE-RP;

b. Observação e registro ${ }^{10}$ das ações dos cursistas no ambiente colaborativo on-line e-proinfo;

c. Acompanhamento gravado em áudio de seis aulas de 50 minutos ( 5 horas de gravação) da professora cursista $L$ em uma escola municipal do interior de São Paulo (Ribeirão Preto) e diários dessas aulas, transcrição ${ }^{11}$ de 3 horas e 44 minutos referente a essas aulas, bem como entrevista realizada com a professora por e-mail em 12-09-2012.

É importante ressaltar que, para a composição desse corpus, a perspectiva orientadora foi a pesquisa qualitativa de cunho etnográfico (ERICKSON, 1984, 1989; STREET, 2011), e, portanto, foram consideradas ainda informações não verbais, além das gravações realizadas, tais como observações das interações entre os sujeitos da pesquisa, dos locais em que se deram os encontros presenciais do ProInfo e a escola de $L$, assim como o entorno destes (DE-RP, SEE, MEC, ensino público paulista, leis e diretrizes ligadas à educação, contexto sócio-político, histórico e cultural).

10 Como os professores publicavam suas atividades na plataforma on-line do curso, os arquivos referentes às suas atividades foram gravados e armazenados em arquivos no formato word. Ao todo foram registradas sete atividades (produção de $H Q$, pôster, elaboração de webquest, construção de mapa conceitual, redação de relato de leitura de um texto, construção de um blog e pesquisa de levantamento na escola) desenvolvidas por cada um dos cursistas, constituindo um conjunto de 65 arquivos. Além disso, foram registradas as interações dos professores cursistas e da tutora em 12 fóruns on-line cujas postagens também se encontram armazenadas em arquivos no formato word e compõem um total de 154 enunciados.

11 Como as aulas foram compostas por vários momentos que não entraram em nossas análises, devido ao nosso foco de interesse, foram transcritos apenas os trechos de gravações em áudio que tematizavam a questão do Blog da professora e dos alunos. As transcrições, das quais alguns excertos aparecerão no artigo, foram orientadas quanto à sua normatização pelos exemplos de Marcuschi (1986/2006). 
O corpus gerado foi devidamente guardado sob sigilo pela pesquisadora que, além de preservar as identidades dos sujeitos, buscou priorizar e tratar de maneira ética $^{12} \mathrm{a}(\mathrm{s}) \operatorname{voz}(\mathrm{es})$ dos atores envolvidos no curso em questão (tutora e professores cursistas) que eram acompanhados de perto. No item que segue, serão apresentadas análises provenientes dos dados coletados para refletir sobre os discursos que predominaram nos três momentos da formação. Embora, no estudo, eles tenham sido trazidos separadamente, na prática, há embricamento deles, aparecendo no artigo em subitens somente para fins analíticos.

\section{ANALISANDO OS TRÊS MOMENTOS DO CURSO DE FORMAÇÃO DE PROFES- SORES PROINFO INTEGRADO}

\subsection{Análise do primeiro momento da formação: o curso "Tecnologias na Educação: ensinando e aprendendo com as TICs" do Prolnfo}

Na primeira unidade do documento, na "Abertura", tem-se a constatação, de acordo com seu texto, de mudanças em várias esferas (sociais, culturais, econômicas, educacionais, científicas etc) que demandariam transformações imperativas no ensino, chamando os professores a tomarem posse do "enquadre da mudança" por meio de asserções tais como "A disseminação do uso de tecnologias, em distintos ramos de atividades, coloca-nos diante de vertiginosas mudanças (...) que precisamos incorporar e lidar em sala de aula" (AMARAL; ARRIADA; RAMOS; SALGADO, 2010, p. 35, grifos nossos), e "A realidade do mundo, na atualidade, requer um novo perfil de profissional e de cidadão que coloca para a escola novos desafios" (AMARAL; ARRIADA; RAMOS; SALGADO, 2010, p. 36 grifos nossos).

Ao nos voltamos para tais passagens, por exemplo, vemos, pela escolha das expressões destacadas, apontamentos para a mudança, para a transformação do status quo existente: "incorporar" implicaria em trazer para o contexto (corpo) algo exterior; o mundo solicita cidadãos novos e "requer" profissionais diferentes, pois mudou e, diante disso, a escola, também teria de se modificar, não podendo se recusar a esse "desafio"; os sujeitos necessitam mudar sempre, serem "contínuos aprendizes" para estar em conformidade com as mudanças constantes do mundo que nos coloca frente a diversas informações.

12 Além da devida autorização cedida pelo Dirigente Regional de Ensino da Diretoria de Ensino da região de Ribeirão Preto para acompanharmos a formação em questão, também foram obtidos Termos de Consentimento Livre e Esclarecido dos sujeitos envolvidos na pesquisa. 
Ao longo das unidades, para promover esse "enquadre da mudança", o documento orienta sobre como se deve agir e demonstra ainda que para mudar, o professor, precisa, primeiramente, passar pelo "enquadre da aprendizagem", oferecendo explicações que se centram na aquisição de competências e habilidades técnicas por parte dos professores que, se souberem lidar com máquinas poderão, consequentemente, impactar suas práticas e as transformar (change) (WARSCHAUER; WARE, 2008).

Mudança essa que é exortada explicitamente em várias passagens do documento, como em "temos certeza de que, conhecendo hipertextos e sendo capazes de produzi-los, sua vida de educador, seja como professor, gestor escolar, seja como aprendiz, nunca mais será a mesma" (AMARAL; ARRIADA; RAMOS; SALGADO, 2010, p. 94) ou "Em todos os canais de comunicação, as tecnologias digitais possibilitam novas maneiras de criação" (AMARAL; ARRIADA; RAMOS, SALGADO, 2010, p. 172). Assim, o material foca na necessidade de, a partir das mudanças, promover a aprendizagem que levaria ao empoderamento de alunos e professores.

Por outra via, reconhecem-se ainda ensaios de uma explanação sobre o "discurso do empoderamento" (WARSCHAUER, WARE, 2008). A seguir, um exemplo em que isso ocorre:

\footnotetext{
No artigo "As sereias do ensino eletrônico", Paulo Blinkstein e Marcelo Zuffo (2001) comentam os "encantos" e as desilusões que as tecnologias trouxeram a várias áreas. Na educação, alertam que, apesar do potencial positivo, o seu uso tem sido, predominantemente, como forma de simples encapsulamento de conteúdo instrucional em mídias eletrônicas. Eles criticam o forte vínculo do propósito educacional com os interesses produtivos capitalistas e defendem que as tecnologias deveriam ser utilizadas, sobretudo, como instrumento de libertação, de engrandecimento da condição bumana (AMARAL; ARRIADA; RAMOS; SALGADO, p. 44, grifos nossos).
}

No início dessa citação fica evidente o que Warschauer e Ware (2008) determinam como "enquadre da aprendizagem", que já foi abordado, interessando-nos, agora, a segunda parte em itálico. Esse trecho se aproxima do que os autores chamam de "enquadre do empoderamento", todavia vai além da concepção dos autores, chamando atenção para uma visão crítica, superior a qualquer pragmática em relação ao poder. Isso demonstra como existem outros enquadres, além dos distinguidos por eles.

Acontece que, ao mesmo tempo em que, no documento, é incorporada essa visão freiriana mais libertária, no material, a menção ao trabalho de Blinkstein e Zuffo (2001 apud AMARAL; ARRIADA; RAMOS; SALGADO, 2010, p. 44) apenas é mencionada, sem qualquer posicionamento ou aprofundamento da discussão a respeito das relações de poder (capitalistas) e o empoderamento dos sujeitos para atingirem suas liberdades valendo-se das tecnologias digitais. 
Ao contrário, depois de recomendar a leitura do artigo, adverte-se: "Talvez você considere a leitura densa, dada sua extensão, e repleta de reflexões complexas" (AMARAL; ARRIADA; RAMOS; SALGADO, 2010, p. 44), desencorajando a leitura do professorado, ao invés de chamar a atenção para a importância do assunto tratado no trabalho, esfriando qualquer tentativa de empoderamento e, reincidindo no discurso de que ao professor bastaria aprender a dominar a técnica da informática e dos programas para efetivar as mudanças requeridas.

Assim, a despeito da proposição que é apresentada na proposta curricular do curso, a saber, privilegiar "as noções de subjetividade - isto é, o protagonismo do aluno e do professor na ação pedagógica - e de epistemologia da prática, ou seja, o conjunto de saberes utilizados pelos profissionais da educação em seu espaço de trabalho cotidiano" (ALMEIDA; PRADO, TORGAGHI, 2010, p. 15), verificou-se, na análise dos dizeres das unidades e nas atividades sugeridas, pouca, ou quase nenhuma promoção ao protagonismo de discentes e docentes.

Na realidade, foi identificado um predomínio do que Warschauer e Ware (2008) tomam como "enquadre da mudança" e certa distorção do que denominam como "enquadre da aprendizagem", uma vez que se volta à tecnologia como objeto e ao professor como sujeito da aprendizagem - diferentemente da visão dos teóricos que tomavam o aluno como centro da aprendizagem - numa espécie de ciclo vicioso em que o mundo teria mudado e exigiria mudanças, cabendo aos professores aprenderem a usar os computadores e a tecnologia educacional para mudarem a escola e, a partir de então, empoderar seus alunos, auxiliando-os a aprender sobre tudo o que esse novo mundo exigiria, ou seja, o enfoque do material está na mudança de postura do professor.

\subsection{Análise do segundo momento da formação: a aplicação do curso pela tutora $A$}

Cada curso conta sempre com um responsável capacitado para sua aplicação, a saber, o formado/tutor. No curso em questão, a formadora será referida como $A$, a qual cumpria sempre as diretrizes do ProInfo. Entretanto, em várias situações, extrapolou orientações advindas do curso, para adaptar o conteúdo ao contexto em que estava, o que põe em relevo uma das características fundamentais dos letramentos que é seu caráter de práticas situadas (HEATH, 1982; 1983), dependentes da interação entre pessoas que realizam ações coletivamente e que passam a fazer sentido aos membros envolvidos, compreendendo o conhecimento como indissociável do contexto. 
No desenvolvimento, por exemplo, da terceira Unidade do Curso, A criou uma atividade que não estava prevista, pois considerou ser importante aos cursistas produzirem algum objeto com a tecnologia para melhor entenderem a teoria que estudavam. Em entrevista, dois dias após o término do curso, afirmou a respeito:

\footnotetext{
Muito bom [o material], dá pra discutir, enxergar como a escola está em relação à tecnologia. Gostei da parte teórica e das atividades. Só mudaria a unidade 3 que é muito 'blá, blá, blá' e ninguém faz. Foi por isso que inventei a atividade da tirinha sonorizada, pra mostrar as várias possibilidades. ${ }^{13}$
}

Como se vê em seu comentário, a tutora, ainda que não previsto no curso, nem do "Guia do Formador", percebeu a necessidade de a turma em questão realizar atividades práticas que pudessem possibilitar vivências que auxiliariam no entendimento ou esclarecimento de conceitos. A considerou imprescindível os professores se colocarem na posição de alunos e produzirem. Assim, levou trechos de diálogos e tirinhas para que os próprios cursistas os sonorizassem com programas disponíveis no computador e os transformassem em vídeos, no MovieMaker - programa que edita vídeos -, parecendo compartilhar a visão do documento analisado no item anterior de que ao aprender a usar a tecnologia, pode-se mudar a prática, ou seja, instruir-se da técnica para promover o "enquadre da mudança".

Outro exemplo de aprendizagem situada promovida pela tutora foi o trabalho com o conceito de hipertexto. Depois de conhecerem-no e realizarem algumas atividades na Unidade 2 do material, os cursistas deveriam desenvolver uma atividade hipertextual com seus alunos, porém, uma das professoras trabalhava em uma escola de periferia onde a tecnologia era totalmente ausente, os alunos não possuíam computadores em suas casas e contato ínfimo ou nenhum com a Internet.

Dessa forma, A desenvolveu, juntamente com a professora, um exercício alternativo em que recortaram trechos de histórias para que os alunos pudessem construir narrativas como quisessem, levando-os a perceber as infinitas possibilidades de produção enunciativa e, por conseguinte, de percepção e interpretação. Com efeito, a professora entendeu o que era o hipertexto e o fato de que, mesmo sem computadores, poderia trabalhar com a ideia do conceito, adaptada à sua sala de aula.

Esse exemplo do hipertexto revela aspectos interessantes. A tutora parte do outro (leia-se professores cursistas e a professora cuja escola não possuía equipamentos tecnológicos) que é projetado no material do ProInfo e estabelece um diálogo respondendo às vozes veiculadas no material, às vozes que ecoam na sociedade,

13 Trecho retirado da entrevista realizada com A em 05 Out. 2012. 
às vozes de outros professores, enfim, há tanto denúncia da falta de estrutura nessas escolas, como inserção dos professores nessa cadeia enunciativa.

A conseguiu mostrar para a professora possibilidades de ação, apesar das adversidades em relação à tecnologia na escola, apontando para a docente que ela está inserida na cadeia enunciativa de que fala Bakhtin/Voloshinov (1929/1988) e pode responder responsiva e ativamente (réplica ativa) ao que foi/é colocado pelo outro como sendo o melhor.

Esse episódio com o conceito de hipertexto aponta para o fato de que as teorias podem chegar aos professores das mais variadas maneiras e, nesse caso, em especial, fica explícito como a responsabilidade por "não saber" a teoria não seria da professora em questão, mas de todas as instâncias (gestão, direção, Estado etc) que não equiparam minimamente a escola daquela comunidade, como deveria ter sido feito e é previsto pelo próprio documento do ProInfo analisado.

Nesse ponto, vê-se que a tutora embasa sua ação/mediação diferentemente do "enquadre do empoderamento" de Warschauer e Ware (2008), ou seja, de forma, inclusive, bastante dialógica, trazendo para o momento da formação as várias vozes sociais, institucionais, políticas e econômicas em embate nas práticas humanas, que permeadas por relações hierárquicas de poder aparecem nesse momento do curso de formação.

Apesar de A buscar fazer com que os professores cursistas enxergassem que eles poderiam ser agentes responsivos e responsáveis e produzir significados com/ nas tecnologias digitais em suas práticas de ensino, durante seus turnos de fala no curso, nas entrevistas e mesmo em conversas informais, notou-se que o discurso explicitado era o do "enquadre do empoderamento" muito próximo à acepção de Warschauer e Ware (2008), uma vez que a tutora limitava-se a reconhecer as transformações que a presença da tecnologia e aprendizado sobre ela ocasionava no ensino, dando "poder" aos professores que poderiam transformar suas práticas de sala de aula, reconhecendo as novas possibilidades de trabalho e os múltiplos letramentos, levando o aluno a "aprender melhor".

\subsection{Análise do terceiro momento da formação: a professora cursista $L$}

Finalmente, depois de acompanharmos o curso e sua aplicação a professores da rede pública, observamos as aulas da cursista e professora da rede $L$. Na instituição onde trabalha, a sala de informática encontrava-se momentaneamente indisponível por problemas técnicos e a despeito disso, $L$ continuava desenvolvendo o trabalho de um blog com os alunos e, nas seis aulas de Ensino Médio que as- 
sistimos, utilizou da lousa e do giz para comentar ações que os alunos fizeram e/ou fariam na tela do computador (que a grande maioria, segundo ela, possuía em casa), desenhando-as.

Um exemplo que ratifica essa articulação dos enquadres, diferenciada dos momentos já analisados, é o que traremos, agora, referente aos dados gerados na observação de uma aula de Biologia ministrada em 31 de Agosto de 2012 para uma turma de primeiro ano de Ensino Médio.

No dia em questão, $L$ solicitava atividade no blog sobre sustentabilidade, a saber, a produção de comentários, pois, segundo ela, os alunos estavam apenas copiando textos sem refletir. ${ }^{14}$ Antes de requerer a tarefa, no entanto, a professora retomou com os alunos como deveriam usar as ferramentas do blog, fazendo revisão quanto a ícones e possibilidades de ação mais técnicas.

Além disso, ela não somente relembrou à turma sobre os procedimentos tecnológicos, mas abordou aspectos acerca do conteúdo e da necessidade de se avaliar a informação e não somente publicar sem se posicionar:

\section{Excerto 1: professora relembra como postar no blog}

1: $L$ : Como é que vai ser o blog (+) A diferença do blog... Como é que postava no blog? ((silêncio e conversas paralelas dos alunos))

2: $L$ : VAMOS, eu to esperando (+). Quem lembra como é que posta no blog?

3: A1: Não sei.

4: A2: Você copia o negócio lá da internet(+), cola lá e posta.

5: L: Não gostei dessa frase! ((Risos na sala))

6: A2: Mas é... uai, a gente posta.

7: L: A parte do POSTAR eu gostei, a parte do COPIAR da internet que eu não gostei.

8: A2: A gente pesquisa.

9: L: Essa parte ficou mais bonitinha $(+)$. Você pesquisa e escreve lá.

10: A2: Isso (+) você pesquisa e cola lá.

11: L: Colar NÃO! ((risos)) Colar é plágio... já expliquei que não pode plagiar um trabalho $(+)$ pode usar como base... Então $(+)$, entra no e-mail da sala, que você tem senha e e-mail,$(+)$ tem a senha. Entra lá que vai aparecer direto o painel de controle, novas postagens. Não é isso? (+) Clicava em novas postagens, quem tá com o modelo antigo. Quem tava com o modelo novo clicava no? No papelzinho $(+)$ na figura do papelzinho.

14 "Eu mudei (+) agora estou obrigando eles a fazer comentários, porque eles só colocam coisa nova, não gostam de comentar, então, agora, eles são obrigados a comentar as postagens ( + ) falar o que eles entenderam... porque ficar muito no blog é ruim... eles mudam as palavras porque eu não deixo copiar, tudo bem, tão tendo um trabalho, mas não tão desenvolvendo $(+)$ agora pra comentar tem que falar o que eles entenderam, discutir com o grupo..." Trecho transcrito do encontro presencial do ProInfo Integrado em 15 de agosto 2012. 
12: A3: Quê?

13: L: Aqui é a figura do papelzinho ((L desenhava a tela e os ícones na lousa)). O blog tem dois modelos, depende do modo que você entra... (+) você pode trabalhar com qualquer um dos dois. No antigo aparece nova postagem. No modelo novo é o papelzinho. Clica nele... (+) aparece a telinha. Não é assim a telinha? Que que vem aqui em cima? ( $L$ apontava para o desenho da tela do computador com o blog que tinha feito na lousa))

14: A1: [Título]

A2: [Título]

15: L: O tí::tulo. Que por sinal, vocês morriam de preguiça de colocar. (+) Que que vinha aqui? O texto? Que não é copiado, é pesquisado. Depois vocês podiam fazer o quê com esse texto?

16: A2: Apagar. ((risos na sala))

17: L: é uma opção $(+)$ pode $(+)$ concordo com você ((irônica)) (+) Que que vocês podem fazer? $(($ Conversinhasnasala $))(+)$ Quequevocêspodemfazercomessetextoaqui? Heim? 18: A1: Colocar imagem.

19: L: Pode colocar imagem, figura. Só figura que pode colocar?

20: A1: Vídeo

21: L: Pode colocar vídeo. E se a letra do texto fosse pequena, o que vocês podiam fazer? $(+)$ Vocês podiam $(+)$ formatar o texto todo. Mudar a letra, mudar a cor $(+)$ chegava no final tinha três opções aqui ((a professora apontava com o giz para a tela $))$. Quais eram as opções? $(+)$ Cancelar? $(($ Burburinhos $))(+)$ Cancelar $(+)$ é $(+)$ postar, rascunho e cancelar. Não gostou $(+)$ se o assunto tive errado, vocês iam e cancelavam. Se vou parar por algum motivo, salva e termina depois, tá? Gostou, entrou no blog, eu corrigi $(+)$ se tiver tudo certo $(+)$ (inaudivel).

22: A1: dava a nota.

23: L: se tivesse certo eu dava a nota. Se tivesse errado? (+) Vocês tinham um prazo pra corrigir $(+) \ldots$

\section{Excerto 2: professora explica nova atividade com o blog}

24: L: Ó::, como é que vocês vão fazer a postagem agora? (+) Vocês vão entrar no blog e selecionar $(+)$ uma postagem que já está lá, tá? (+) Não vão colocar defeito na postagem, exemplo não gostei da cor, não gostei do que tá escrito $(+)$ vocês podem $(+)$ vocês tem direito a não gostar do assunto, mas não colocar defeito no serviço do outro, tá certo? $(+)$ não confundam uma coisa com outra. /.../Vocês vão escolher qualquer postagem do $1^{\circ} \mathrm{A}$. Só do primeiro A vocês vão fazer agora, tá? (+) Então chega lá no blog, nós tamos com cento e tantas postagens. O blog de vocês tá carregadinho. Precisa ler todas? O ideal seria, mas eu sei que a preguiça impera na sala. Então, vocês vão ler pelo menos a do $(+) 1^{\circ} \mathrm{A}$. Como vocês sabem que é do $1^{\circ} \mathrm{A}$ ? Aparece embaixo o e-mail, cadastro da sala. Lê a postagem, escolhe a que vocês mais gostaram e a que vocês menos gostaram em 
relação ao assunto" não é em relação à pessoa, tá? E vão comentar essa postagem. Embaixo dessa postagem vai ter a opção 0 comentário, tá? (+) 1 comentário: depende $(+)$ quando aparecer a palavra comentário, vocês escolheram a postagem $(+)$ vai lá e coloca $(+)$ comentário $(+)$ vai aparecer a postagem original em cima escritinha certinho que vocês escolheram e uma caixa em branco em baixo da postagem. Então, não precisa ficar com medo "Ah, eu vou esquecer o que tá escrito". Ela aparece na tela. Você tem a tela assim. (( $L$ desenha a tela na lousa $)$ )

25: E ai, vocês vão comentar. Como é que vocês vão comentar? "Adorei a postagem, achei super interessante". Valeu? ((Burburinhos))

26: L: Valeu ou não valeu?

27: A4: Valeu!

28: L: Não valeu:: Que que vocês vão fazer? (+) Escreve o que vocês gostaram. A A1 falou direitinho, é que vocês tavam conversando aí e não escutaram. Vai argumentar $(+)$ Gostou da postagem? Gostei! Argumenta:: por que que você gostou $(+)$ tá? Então, ontem $(+)$ não, foi antes de ontem, eu tava corrigindo as postagens que tavam lá e tinha uma postagem que tava "eu gostei...", da sacola plástica , e tava "eu gostei e tal porque não é a população (+) não é sacola plástica que polui o ambiente, é a população..." ela começou um assunto interessante, só que ela tinha que continuar esse assunto. Ela tinha que perguntar o que a população tinha que fazer pra evitar a contaminação? Sugere alguma coisa $(+)$ dentro do tema que a gente tá $(+)$ Então o assunto começou interessante e parou (inaudível) Então vamos voltar aqui. Leu tal e comentou $(+)$ Você tem duas opções aqui embaixo ((ela aponta para a lousa)): publicar e cancelar, tá? Publicou $(+)$ aqui tem uma coisa interessante $(+)$ aqui não edita $(+)$ a postagem você não tem direito a editar (+) Publica, ela aparece no blog e ela vai me avisar lá no e-mail que vocês postaram. Se tiver alguma aberraçã::o da natureza, vocês vão ver que a postagem vai desaparecer $(+)$ eu vou simplesmente apagar a postagem. Depois, quando eu voltar na sala, eu até falo porque que eu apaguei, mas não vai dar pra deixar uma semana lá, principalmente, porque o comentário não se edita, não tem como a gente entrar e complementar comentário, $(+)$ quando vocês tiverem que consertar comentário, vão ter que apagar o comentário $(+)$ por isso que eu to explicando direitinho, to dando exemplo pra evitar esse tipo de trabalho. Se precisar, vocês fazem $(+)$ tudo bem. Se for só consertar $(+)$ Teve um aluno que escreveu, não é dessa escola, é do outro blog exemplo com "s", quase que eu surtei quando eu vi aquilo.

29: A4: Dá zero pra ele.((risos na sala))

30: L: Até acredito que tenha sido na correria, na correria de digitar, embora o " $\mathrm{x}$ " fica longe do "s", mas $(+)$ tava correndo lá $(+)$ só que dá pra deixar num blog com o nome da escola "exemplo" com "s"? Dá ou num dá?

31: A1: Não!

32: L: Por isso que eu apago (inaudível). Então se eu apagar porque teve algum erro de português ou alguma concordância verbal muito feia $(+)$ vocês têm direito a refazer, só apaguei porque tá no blog na escola. Se eu apagar por uma daquelas 
brincadeiras, você não vai ter direito à correção. Entenderam como é que vai funcionar? Só $1^{\circ}$ A vocês vão comentar $(+)$ nesse momento...

Ao examinarmos as ações da professora nos excertos transcritos, vê-se que ela ultrapassa o "enquadre da aprendizagem" - limitado ao desenvolvimento de habilidades para usos de ferramentas para ações de ensino-aprendizagem, conforme Warschauer e Ware (2008) - quando não se restringe a ensinar os alunos a usarem tecnicamente o blog (postar, inserir comentário, cancelar, colocar figuras): $L$ dá orientações quanto à forma do texto (cor e tamanho das letras, extensão e estrutura) e ao conteúdo (alertando os estudantes sobre assuntos pertinentes, a importância da pesquisa e da crítica, como no caso da sacola plástica e da necessária elaboração de uma argumentação).

Ademais, $L$ aborda a ética, ao relacionar questões acerca de propriedade intelectual e autoria, do respeito pela produção dos colegas da classe e das outras turmas da escola, moderação em publicações no meio digital (ela, por exemplo, apaga os comentários impróprios).

Com efeito, a professora trata o blog como plataforma para postagem de textos argumentativos públicos, ao mesmo tempo em que se utiliza uma ferramenta, explicitando os critérios de exclusão de algumas postagens em relação ao conteúdo, quando poderia simplesmente apagar os comentários sem deixar as razões claras para seus autores (alunos), relevando, pois, sua consciência sobre o caráter público-privado de um blog.

Assim, ao tomarmos por base que os gêneros são "tipos relativamente estáveis de enunciados" e que "esses três elementos - o conteúdo temático, o estilo, a construção composicional - estão indissoluvelmente ligados no todo do enunciado" (BAKHTIN, 1952-1953/2003, p. 261), conclui-se que a professora trabalha com uma ótica de gêneros, quando considera em concomitância elementos estruturais, do conteúdo e das possibilidades estéticas (e éticas) que seus alunos podem utilizar nas postagens do blog, revelando, concomitantemente, a consciência de que um blog é uma plataforma que veicula gêneros importantes, ressaltando para os alunos que, em vista disso, ela espera uma postagem na forma de texto argumentativo, ou seja, um post $t^{15}$ como gênero, ação que, provavelmente, ela não aprendeu no curso de formação.

Por outro lado, a docente também sinaliza que leva em conta o contexto situacional dos alunos, mostrando que os posts são muitos para serem comentados e,

15 Post $=$ postagem no blog. 
portanto, faz uma seleção deles (uma sala), ou seja, estabelece um diálogo com seus alunos não só no nível da sala de aula, mas do dialogismo pleno, sinalizando para a interlocução entre ela, seus alunos e os próprios leitores do blog, diferentemente do diálogo que (não) foi estabelecido com ela por outras instâncias, como o Estado, a gestão, os idealizadores do curso de formação.

Além disso, a professora sabe que os alunos têm acesso às tecnologias digitais, familiaridade com blogs e com a prática de comentários, os quais realizam, cotidianamente, em redes sociais da Internet. Sua proposta é, então, partir do já dito/ visto (CORRÊA, 2004) pelo alunado para modificar suas ações na rede, promovendo usos mais críticos das ferramentas tecnológicas, adotando, assim, o "enquadre da mudança", conforme Warschauer e Ware (2008). Ela tenciona modificar o "olhar" dos discentes sobre o que já praticam; transformar práticas escolares tradicionais e repudiadas pelos alunos, trazendo as TDIC para o contexto educacional ${ }_{i}$ mudar a visão acrítica que, supostamente, alunos teriam sobre determinados assuntos sociais.

Finalmente, pela análise dos excertos acima e em todo o material coletado, concernente aos enunciados de $L$, percebe-se que a docente não pode se desvencilhar de questões institucionais (dá pra deixar num blog com o nome da escola "exemplo" com "s"? Dá ou num dá? (...) Por isso que eu apago"/"eu corrigi"), entre outras, direcionando as atividades dos alunos para possibilidades de fazerem algo distinto do convencional (livro impresso, prova, lista de exercícios), porém, balizando sempre o que devem ou não fazer com as TDIC para obterem notas boas.

Assim, ela não chega a uma incorporação do "discurso do empoderamento" de Warschauer e Ware (2008) ou de Freire (1970), mas demonstra a legitimação de valores que a diferenciam de professores que cessam suas ações pela ausência de condições estruturais, o que quase nunca é ensinado e explicitado por meio de teorias em cursos de formação, como observamos também no Proilnfo.

\section{CONCLUSÃO}

Fetichizar as tecnologias, defendê-las ou combatê-las por conta das exclusões e inclusões que possibilitam não é uma atitude tão produtiva quanto tentar entender os caminhos pelos quais todas as tecnologias, inclusive as TIC, são incorporadas a um mundo de desigualdades estruturais crescentes, bem como os caminhos pelos quais ajudam a transformá-lo (BUZATO, 2006, p. 82).

Nas análises pontuais do corpus coletado e aqui trazidas, tencionou-se identificar como as três concepções - no que tange os discursos sobre letramentos e 
tecnologias delineados por Warschauer e Ware (2008), entre tantas outras possíveis - emergiram com frequência e se entrelaçaram nos momentos da formação para tentar desfazer a existente dicotomia demonstrada ao longo do artigo, entendendo "os caminhos pelos quais todas as tecnologias, inclusive as TDIC são incorporadas a um mundo de desigualdades" como aparece na epígrafe desta seção.

De modo geral, com base nos dados, foi possível detectar preponderância do "discurso da mudança" ecoando nos dizeres do material do curso "Tecnologias na Educação: ensinando e aprendendo com as TICs" do Prolnfo como a justificativa do "enquadre da aprendizagem" que, pode ou não levar ao empoderamento. Essa postura do curso pode ser explicada pelos objetivos a que esse se presta e, por conseguinte, seu material, a saber, ampliar índices de professores da rede estadual aptos a utilizar tecnologias digitais em suas salas de aula a fim de atender a demanda social e econômica e colocar o Brasil em bons rankings.

Diferentemente, a análise da aplicação do curso em situação específica revelou que o "discurso do empoderamento" prevalecia sobre o "discurso da mudança" e o "discurso da aprendizagem", à medida que a tutora $A$ reconhecia as complexidades socioculturais, políticas e econômicas, suscitando seus cursistas a se empoderarem diante das novas mídias e tecnologias digitais, quando produziam objetos culturais, além de considerar todo o contexto de ensino relacionado a outras esferas de ação humana, colocando o empoderamento dos professores como o ponto de partida para aprender a usar as TDIC e, supostamente, mudar, de forma positiva práticas escolares e o aprendizado dos próprios alunos.

Enfim, no acompanhamento de uma professora cursista em sua prática docente, viu-se que o discurso privilegiado era o da mudança, embora, para instituí-lo, a professora $L$, com frequência, tenha necessitado valer-se do "discurso da aprendizagem" e, é preciso ressaltar, o modo como a professora articulava os discursos era bem diferente da perspectiva colocada por Warschauer e Ware (2008), o que corrobora o fato de que essa não é a única possível.

Assim, este trabalho é concluído, advertindo que os três tipos de discurso envolvendo tecnologias e letramentos distinguidos Warschauer e Ware (2008) permeiam a relação ensino e tecnologias digitais, ainda que em contextos específicos um possa se sobrepor ao outro ou que novas articulações não previstas por eles possam emergir. É preciso dizer, no entanto, que, pela análise dos dados, não foi possível identificar uma linha clara de separação entre eles, pois é imprescindível pensarmos nas relações de poder que influenciam o uso das TDIC, reconhecendo os limites e possibilidades de protagonismo dos sujeitos. 
Nesse sentido, talvez seja necessário articular as teorias de linguagem (digital) ao utilitarismo liberal existente e à hegemonia da mídia em sua manutenção para propor algumas mudanças nesses cursos de formação que, equivocamente, partem do pressuposto de que as instâncias relacionadas à educação estariam separadas, gerando uma desarticulação entre teoria e prática, como pudemos perceber nas análises.

Fechando o artigo, suscitamos uma reflexão acerca de tantas divisões categóricas que ocorrem na atualidade, como tecnologias $x$ letramentos, teoria $x$ prática, técnica $x$ conteúdo, entre outras, e, chamamos a atenção de todos, inseridos na área de educação e linguagem, a pensar não dicotomicamente, mas considerando todas as relações de poder e configurações políticas, econômicas, sociais e culturais em que os sujeitos estão envolvidos para entender as tecnologias digitais educacionais e suas possibilidades para o ensino, ao invés de tão somente valorizá-las ou repudiá-las.

\section{REFERÊNCIAS BIBLIOGRÁFICAS}

ALMEIDA, M. E. B.; PRADO, M. E. B. B.; TORGAGHI, A. J. C. (2010). Tecnologias na educação: ensinando e aprendendo com as TICs - Guia do Cursista. Brasília: Secretaria de Educação à Distância.

AMARAL, A. L.; ARRIADA, M, C; RAMOS, E, M, F; SALGADO, M, U, C. (2010). Tecnologias na educação: ensinando e aprendendo com as TICs - Guia do Formador. Brasília: Secretaria de Educação à Distância.

BAKHTIN, M. M. (1952-1953/2003). Os gêneros do discurso. In: Estética da criação verbal, trad. Paulo Bezerra, 4. Ed. São Paulo: Martins Fontes, pp. 261-306.

BAKHTIN, M, M.;VOLOSHINOV, V. N. (1929/1988) Marxismo e Filosofia da Linguagem. Tradução Michel Lahud e Yara Frateschi Vieira. 4. ed. São Paulo: Editora Hubitec.

BRASIL. Portaria nº 522/1997. Brasília: Ministério da Educação e Cultura - MEC.

BRESSANI, J. A. Políticas de Formação Continuada de Professores em Mato Grosso: uma análise discursiva do programa GESTAR. (2012). Tese de Doutorado em Linguística. Instituto de Estudos da Linguagem, Unicamp, Campinas.

BUCKINGHAM, D. (2010). Cultura digital, educação midiática e o lugar da educação. Educ. Real. v. 35. n⿳0. 3, pp. 37-58.

BUNZEN, C. (2011). A fabricação da disciplina escolar Português. Rev. Diálogo. Educ., v. 11, $\mathrm{n}^{\circ} 34$, pp. 885-911.

BUZATO, M. E. K. (2006). Letramentos Digitais e Formação de Professores. In: III Congresso IBERO-AMERICANO EDUCAREDE. São Paulo: CENPEC, pp.81-86.

CORRÊA, M. L. G. (2004). O modo beterogêneo de constituição da escrita. São Paulo: Martins Fontes. 
DE GRANDE, P. B. (2011). Construções de identidades profissionais na interação: algumas implicações para a formação continuada do professor. In: Fórum Linguístico, v. 8, no 2, pp. 145-158.

ERICKSON, F. (1984). What makes school ethnography "ethnographic'?". Antbropology and Education Quarterly, v. 15, n⿳0.1, pp. 51-66.

ERICKSON, F. (1989) Metodos cualitativos de investigación sobre la enseñanza. In: Wittrock, M. C. (Org.). La investigación de la enseñanza II: métodos cualitativos y de observación. Barcelona: Paidos, pp. 195-301.

FREIRE, P. (1970). Pedagogia do oprimido. Rio de Janeiro: Terra e Paz.

HEATH, S. B. (1983). Ways with words. Cambridge: Cambridge University Press.

HEATH, S. B. (1982). What no bedtime story means: Narrative skills at home and school. In: Language in society, v. 11, n. 2 pp.49-76.

MARCUSCHI, L. A. (1986/2006). Análise da conversação. São Paulo: Ática.

PROINFO. (2010). Tecnologias na educação: ensinando e aprendendo com as TICs. Brasília, Secretaria de Educação à Distância.

VALENTE, J. A. (1993). Por quê o computador na educação? In: José A. Valente (org.). Computadores e Conbecimento: repensando a educação. Campinas: Unicamp/Nied, pp. 24-44.

STRAUB, S. L. W. (2012). Política de Informática na Educação: o Discurso Governamental. Tese de Doutorado em Linguística. Instituto de Estudos da Linguagem, Unicamp, Campinas.

STREET, B. (2011). Literacy inequalities in theory and practice: The power to name and define. In: Journal of Educational Development, v. 31, n. 6, pp. 580-586.

WARSCHAUER, M., \& WARE, M. (2008). Learning, change, and power: Competing discourses of technology and literacy. In: Coiro, J.; Knobel, M.; Laskshear, C. \& Leu, D. J. (Orgs.). Handbook of research on new literacies. New York: Lawrence Erlbaum Associates, pp. 215-240.

Recebido: $16 / 09 / 2013$

Aceito: 07/04/2014 